\title{
Web-Wise
}

\section{World Intellectual Property Organization}

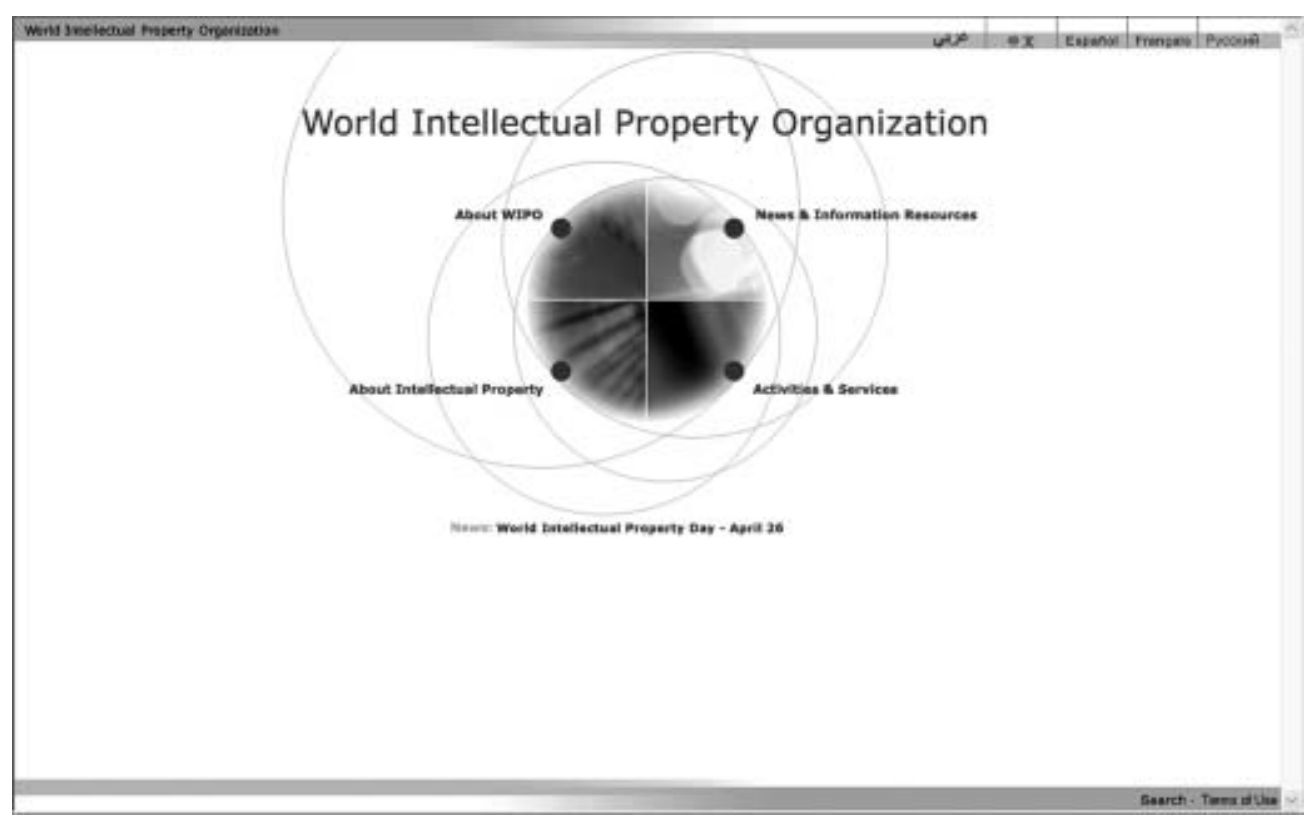

www.wipo.int

One of the intense legal buzzwords of the late 1990s through today is "Intellectual Property Rights" (IPR). The issue was first raised in 1873, when foreign exhibitors refused to display their products at the International Exhibition of Inventions in Vienna because they were afraid that their ideas would be stolen and used for monetary gain by people in the other countries. In order to address these fears the Paris Convention for the Protection of Industrial Property was signed in 1883 which paved the way for an international design to help inventors protect their intellectual creations from being pirated by others.

Today, intellectual property is a knotty, multidimensional concept covering the arts, printed media, the Internet, and industry. For the scientific and healthcare community it refers to any legal rights relating to the creations of the human mind which could be industrial, artistic, scientific or literary in nature.

The World Intellectual Property Organization (WIPO) was founded in 1967 to encourage respect of intellectual property throughout the world and to ensure that intellectual property rights are maintained and enforced. It currently has 179 nations as members and works as a specialized agency of the United Nations.

The Intellectual Property Rights law is meant to safeguard the creations of inventors and creators of intellectual goods and services. The two major categories of intellectual property created and protected by the Paris and Berne Conventions pertain to Industrial property - inventions, trademarks and industrial designs, and Copyright. Intellectual property concerns are of prime importance in medicine research and manufacture and it is the area of copyright that poses most of the issues for research related to pharmaceuticals.

The WIPO website (http://www.wipo.int/) seeks to tackle the fundamental questions relating to these issues. It has a simple and easily navigable design with a comprehensive search facility, essential for a repository of such proportions. Besides the usual information about the organization, the "About WIPO" link renders details about the various treaties and historical facts that led to its evolution. The "About Intellectual Property" page has the most remarkable and pertinent information about Industrial Property, Inventions (patents), Trademarks, Industrial Designs, Geographic Indications, Copyright and Related Rights, Emerging Issues in IP and Intellectual property in everyday life. The latter includes a virtual tour which seeks to educate on the importance of human creativity and invention, its application and impact on day-to-day living. It also aims to demystify the concept of copyright and patents in order to discourage piracy. 
The "News and Information Resources" is the access point to various laws that govern Intellectual property and copyright issues. The Collection of Laws for Electronic Access (CLEA) is a unique ready reckoner for various rulings and related documents. The "Activities and Services" link takes one to various links on the actual process of obtaining and retaining a patent. This link is loaded with resources and advice on the procedures for patenting, IP, copyright and their application in various trades and commercial enterprises. The links on "Traditional Knowledge" and "Innovation Promotion" are relevant to the developing countries in terms of original research and discovery initiatives. A number of documents on scientific processes and pharmaceutical research are available. The monograph 'Striking a Balance: The Patent System and Access to Drugs and Health Care' and on non-proprietary names makes for thought-provoking reading. Success stories in relation to patents and cheaper medicines are interspersed. The case reports on the initiative of an Indian pharmaceutical company to facilitate easy availability of anti HIV drugs makes for inspirational reading as does the one on a small Croatian pharmaceutical company that discovered azithromycin and after patenting it went on to evolve as one of the largest companies in Eastern Europe.

As India gears up to implement the global agreement on Trade-Related Intellectual Property Rights (TRIPs) by 2005 it has to refocus its $R$ \& D activities on diseases which are particular to developing countries. The spotlight has to be on the development of the domestic pharmaceutical industry and optimum use of Intellectual Property Rights as an opportunity to create a better research environment. The myriad contents of the WIPO website will help provide the necessary guidelines and background to help implement intellectual propertyrelated issues in the right perspective.

J. Singh

Website Editor, IJP

E-mail: jatindersingh@vsnl.com

\section{Journal of Postgraduate Medicine}

The official publication of Staff Society of Seth G. S. Medical College of K. E. M. Hospital, India

on occassion of its Golden Jubilee presents

\section{JPGM Gold Con: 50 years of Medical Writing}

An International Conference on Medical Writing, Editing and Publishing

23rd-26th September 2004, Mumbai, India

\section{Highlights of the program}

\section{Program on Writing}

Scientific papers: structure \& getting started Importance of 250 words (Abstracts)

Illustrating a paper

Dealing with journals

Statistics

Looking out for references

Clinical practice and publishing

Research Integrity and Publication Ethics

The future of scientific publishing

Program on Editing
Peer review process
Dealing with authors
Ethical issues
Journal indexing
Quality parameters
Society run journals
Style and print
Financial and legal aspect
Industry and journals

\section{Faculty and Advisors}

Philip Abraham

Rakesh Aggarwal

Doug Altman

Subbiah Arunachalam

S. K. Bichile

Amy Brand

Leslie Chan

Ranjit Roy Choudhury

Alastair Dryburgh

Julie Esanu

Barbara Gastel
Jaideep Gogtay
Jean-Claude Guédon
Stevan Harnad
Bruce Hugman
Tom Jefferson
R. J. Jha
S. P. Kalantri
Rajendra Kale
Thomas Lang

Kiran Marthak

Ana Marusic

R. A. Mashelkar

Faith McLellan

Hooman Momen

Sally Morris

Arun Nanivadekar

Samiran Nundy

Ivan Oransky

Roy M. Pitkin

Program on E-publishing
Impact of open access
Good e-publication guidelines
Electronic journal management
Open access and e-publishing initiatives
Archiving: Self and institutional
Who pays for open access?
Economic models for open access journals
Solutions for the developing world
Failures, successes and future

\section{Contact Details}

Editor, Journal of Postgraduate Medicine,

Department of Neurosurgery, Seth G.S. Medical College and K. E. M. Hospital, Parel, Mumbai - 400012 , India

Phone: 91-022-24129884; Fax: 91-022-25032398; Website: www.jpgmonline.com/goldcon.asp 